\title{
Assessment of Electrolyte Free Water Clearance in Renal Transplant Recipients
}

\author{
Abbasali Zeraati, ${ }^{1}$ Maryam Hami, ${ }^{1,}$ Farzaneh Sharifipour, ${ }^{1}$ and Mohammad Reza Reyahi ${ }^{2}$ \\ ${ }^{1}$ Department of Nephrology, Kidney Transplantation Complications Research Center, Faculty of Medicine, Mashhad University of Medical Sciences, Mashhad, IR Iran \\ ${ }^{2}$ Kidney Transplantation Complications Research Center, Mashhad University of Medical Sciences, Mashhad, IR Iran \\ "Corresponding author: Maryam Hami, Department of Nephrology, Kidney Transplantation Complications Research Center, Faculty of Medicine, Mashhad University of \\ Medical Sciences, Mashhad, IR Iran. E-mail: hamim@mums.ac.ir
}

Received 2015 April 19; Accepted 2015 April 19.

\begin{abstract}
Background: Few studies have been done on free water excretion capacity in renal transplant recipients.

Objectives: This study was designed to compare electrolyte free water clearance(E-CH2O) in renal transplant recipients with healthy control group.

Methods: A cross-sectional study was conducted to determine three-hour creatinine clearance (CCl), E- $\mathrm{CH}_{2} \mathrm{O}$, and percent urine output in 3 hours after administering $20 \mathrm{~mL} / \mathrm{Kg}$ oral water loading following 12-hour fasting, in 22 renal transplant recipients with good graft function (creatinine $<1.5 \mathrm{mg} / \mathrm{dL}$ ) and 26 healthy controls. Patients with diabetes mellitus, hypertension, ischemic heart disease, or liver disease, hypovolemia and hypoalbuminemia were excluded. Statistical analysis was done using t-test, K-square, and Pearson's correlation test.

Results: We recruited 25 recipients (73\% patients in living and $27 \%$ in cadaveric donor transplantation) and 26 healthy control groups.3 patients refused to collect urine and finally 22 patients finished the protocol. The mean age of subjects was $37.68 \pm 13.88$ and $31.40 \pm 8.20$ years old in renal transplant recipients and control groups, respectively. In patient group male to female ratio was 9/13 and in control group was14/12. Although the 3h-CCl was similar (126.49 $\pm 53.52 \mathrm{vs.} 109.99 \pm 47.06 \mathrm{~mL} / \mathrm{min})$ in two groups (P $>$ $0.05)$, the $\mathrm{E}-\mathrm{CH} 2 \mathrm{O}(1.83 \pm 1.22$ vs. $2.94 \pm 2.02)$ and 3-hour urine output percent ( $55.93 \pm 22.86$ vs74.11 \pm 30.38$)$ in kidney recipients was significantly lower than healthy controls $(\mathrm{P}<0.05)$. There wasn't any significant correlation between E- $\mathrm{CH} 2 \mathrm{O}$ and $3 \mathrm{~h}-\mathrm{CCl}$ in renal transplant recipients. Donor source and gender did not affect $3 \mathrm{~h}-\mathrm{CCl}$ and E-CH2O in renal transplant patients.

Conclusions: This study demonstrated that $\mathrm{E}-\mathrm{CH}_{2} \mathrm{O}$ has been decreased in renal transplant patients in comparison with control group when there was not any difference between $3 \mathrm{~h}-\mathrm{CCl}$ in two groups. This indicates that $\mathrm{E}-\mathrm{CH}_{2} \mathrm{O}$ may be decreased earlier than 3h-CCl in transplant patients.
\end{abstract}

Keywords: Kidney Transplantation, Water-Electrolyte, Clearance

\section{Background}

Water is the most abundant constituent in the body, accounting for $50 \%$ of body weight in women and $60 \%$ in men. Kidneys have main role in water homeostasis and regulation of plasma osmolality [1]. As plasma osmolality changes can produce serious neurologic symptoms, so it is maintained within narrow limits by appropriate variations in water clearance [2]. Kidneys are able excrete or reabsorb water without solute to balance plasma osmolality [3]. It is assumed that evaluation of electrolyte free water clearance $\left(\mathrm{E}-\mathrm{CH}_{2} \mathrm{O}\right)$ gives us useful data about regulation of plasma osmolality by the kidneys in normal condition. However $\mathrm{E}-\mathrm{CH}_{2} \mathrm{O}$ can be changed in renal tubular damage. Moreover than serum osmolality, salt reabsorption in ascending loop of Henle effects on final calculated E- $\mathrm{CH}_{2} \mathrm{O}$.

One of the most common of drugs that used routinely in transplant patients are calcineurin inhibitors like cy- closporine and tacrolimus Nephrotoxicity is a well-known side effect of these drugs. Kidney biopsy in renal transplant recipients with normal creatinine clearance showed early signs of tubular damage due to rejection or drug toxicity. In practice, the creatinine clearance $(\mathrm{CCl})$ which is a marker of glomerular function often used to estimate renal function and nephrotoxicity. However tubular damage is even earlier finding than glomerular involvement, then E-CH2O may be works as a marker of tubular function and it can be used for detection of graft damage even sooner than creatinine clearance (CCL) [4].

\section{Objectives}

In this study we tried to compare this part of renal function in healthy volunteers with kidney transplant recipients with good graft function. 


\section{Methods}

This cross sectional study was performed in Montaserieh transplant center in the Mashhad University Medical Sciences as a prospective, cohort trial in adult renal transplant recipients. All kidney transplant patients who meet eligibility criteria selected and entered to study. These criteria were consisted: age more than 15 years old, serum creatinine less than $1.5 \mathrm{mg} / \mathrm{dL}$, transplantation duration more than 6 months, no known systemic disease that may effect on renal function, like hypertension, diabetes mellitus, ischemic heart disease, liver disease, taking any drug that could lead to serum creatinine level elevation such as Co-trimoxazol and Cimetidine, no diuretic prescription, no proteinuria more than $500 \mathrm{mg} /$ day and serum Albumin less than $3.5 \mathrm{~g} / \mathrm{dL}$.The accepted immunosuppressive regimen in this study was included cyclosporine, mycophenolate mofetile, and low dose prednisolone.

The eligibility criteria for control group were: age more than 15 years old, serum creatinine less than $1.5 \mathrm{mg} / \mathrm{dL}$, no known renal and systemic disease, and not taking any medication.

Following a $12 \mathrm{~h}$ fast, participants were weighed in the early morning and $20 \mathrm{~mL} / \mathrm{kg}$ oral water loading was administered over 30minutes. After the water loading was completed, urine output was collected for $3 \mathrm{~h}$ without a urinary catheter. Participants were kept in a sitting position, only standing to void. Urine output after 3 hours was recorded and $10 \mathrm{~mL}$ urine as well as blood was obtained to measure urine $\mathrm{Na}, \mathrm{K}$, creatinine, as well as plasma $\mathrm{Na}$ and creatinine concentrations. Three-hour $\mathrm{CCl}, \mathrm{E}_{-} \mathrm{CH}_{2} \mathrm{O}$, and estimated $\mathrm{CCl}$ (CClest) were calculated according to the formulae presented in Box 1.The study was approved by the Ethical Committee of the Mashhad University of Medical Sciences.

Box 1. Formulas for Calculation of Creatinine Clearance and Electrolyte Free Water Clearance

\begin{tabular}{l}
\hline Formulas \\
\hline $\mathrm{E}-\mathrm{CH}_{2} \mathrm{O}=\mathrm{V} \times(1-\mathrm{UNa}+\mathrm{UK} / \mathrm{PNa})$ \\
$\mathrm{CCL}=\mathrm{V} \times \mathrm{Ucr} / \mathrm{Pcr}$ \\
$\mathrm{CCLest}(\mathrm{men})=(140$-age $) \times$ weight $/ 72 \times \mathrm{Pcr}$ \\
CCLest $($ women $)=[(140$-age $) \times$ weight $/ 72 \times \mathrm{Pcr}] \times 0.85$ \\
Urine output $\%=$ urine output $/$ water intake $\times 100$ \\
\hline
\end{tabular}

E- $\mathrm{CH}_{2} \mathrm{O}$, electrolyte free water clearance $(\mathrm{mL} / \mathrm{min}) ; \mathrm{V}$, urine output (mL/min); UNa, urinary $\mathrm{Na}$ after water loading $(\mathrm{mEq} / \mathrm{L})$; UK, urinary $\mathrm{K}$ after water loading (mEq/L); $\mathrm{PNa}$, plasma $\mathrm{Na}$ after water loading (mEq/L); CCl, creati- nine clearance; Ucr, urinary creatinine after water loading $(\mathrm{mg} / \mathrm{dL})$; Pcr, plasma creatinine after water loading $(\mathrm{mg} / \mathrm{dL}) ;$ CClest, estimated creatinine clearance according to Cockcoft-Gault formula.

\subsection{Statistical Methods}

Categorical variables were compared between patient and control groups by Chi-square test. Continuous variables between these two groups were evaluated by using independent t-test analysis. They were expressed as mean values \pm standard deviations. Pearson correlation was used for detection of correlation between water clearances in two groups. Statistical analysis was performed using SPSS for Windows (Version 11.0, SPSS Inc.). P value less than 0.05 considered significant.

\section{Results}

Totally 51 participant [patient group $(n=25)$, control group $(n=26)$ ] entered to study. 3 patients refused to collect urine and finally 22 patients finished it. Renal transplant recipients received their graft from cadaveric donors in 6 patients (27\%) and living donors in 16 patients (73\%).The mean of post-transplant period in patient group was 65.58 \pm 50.95 months. The mean of cyclosporine dosage and its trough level in patient gruop were $2.98 \pm 1.06 \mathrm{mg} / \mathrm{kg}$ and $102 \pm 24.3 \mu \mathrm{g} / \mathrm{L}$ respectively. Clinical and laboratory features of the study population are presented in Table 1 .

Table 1. Demographic and Laboratory data of Study Population

\begin{tabular}{lccc}
\hline Variables & $\begin{array}{c}\text { Patients Group }(\mathbf{N}= \\
\text { 22) }\end{array}$ & $\begin{array}{c}\text { Control Group }(\mathbf{N}= \\
\mathbf{2 6})\end{array}$ & P Value \\
\hline Age & $37.68 \pm 13.88$ & $31.40 \pm 8.20$ & 0.08 \\
\hline Gender $(\mathbf{M} / \mathbf{F})$ & $9 / 13$ & $14 / 12$ & 0.401 \\
\hline Weight, kg & $61.80 \pm 11.14$ & $69.35 \pm 10.91$ & 0.02 \\
\hline Sys BP & $131.20 \pm 14.31$ & $119.26 \pm 12.89$ & 0.003 \\
\hline Dia BP & $86.92 \pm 7.42$ & $81.48 \pm 11.01$ & 0.02 \\
\hline Plasma Na & $141.73 \pm 2.51$ & $142.73 \pm 3.34$ & 0.253 \\
\hline Plasma K & $4.35 \pm 0.53$ & $4.29 \pm 0.40$ & 0.692 \\
\hline Plasma Crt & $0.21 \pm 1.02$ & $0.18 \pm 0.85$ & 0.02 \\
\hline Urine Na & $64.13 \pm 36.77$ & $50.19 \pm 45.74$ & 0.257 \\
\hline Urine K & $9.99 \pm 14.62$ & $10.80 \pm 6.79$ & 0.801 \\
\hline Urine vol. & $687.27 \pm 285.81$ & $989.61 \pm 415.31$ & 0.006 \\
\hline Urine Crt & $28.54 \pm 10.38$ & $20.71 \pm 11.98$ & 0.021 \\
\hline
\end{tabular}

Based on the data, we calculated Glomerular Filtration Rate(GFR), creatinine clearance, urine output percentage, and free water clearance in both patients and control groups. The result was shown in Table 2. 
Table 2. Calculated GFR, Creatinine Clearance, Urine Output Percentage in Patients and Control Groups

\begin{tabular}{lccc}
\hline & $\begin{array}{c}\text { Patients Group }(\mathbf{N} \\
\mathbf{2 2 2})\end{array}$ & $\begin{array}{c}\text { Control Group } \\
(\mathbf{N}=\mathbf{2 6})\end{array}$ & PValue \\
\hline CrCl, $\mathbf{~ m L} / \mathbf{m i n}$ & $101.99 \pm 47.06$ & $120.88 \pm 51.92$ & 0.197 \\
estGFR & $88.54 \pm 26.71$ & $130.36 \pm 130.36$ & 0.000 \\
Urine output, \% & $55.93 \pm 22.86$ & $74.11 \pm 30.38$ & 0.03 \\
E-CH $\mathbf{O}$ & $1.83 \pm 1.22$ & $2.95 \pm 1.98$ & 0.026 \\
\hline
\end{tabular}

Abbreviations: $\mathrm{CCl}$, creatinine clearance; $\mathrm{E}-\mathrm{CH}_{2} \mathrm{O}$, electrolyte free water clearance (mL/min); est GFR, estimated GFR.

There wasn't any difference between age and gender of patient and control groups $(\mathrm{P}>0.05)$. Comparison between two groups showed that serum and urine electrolytes such as sodium, potassium were similar $(\mathrm{P}>0.05)$. Although plasma creatinine was significantly lower in control group than patients $(\mathrm{P}<0.05)$, it was in normal range in all of patients and also after calculation of creatinine clearance there wasn't significant difference between two groups ( $P>0.05)$. After calculation estimated GFR (est GFR) by Cockroft-Gault formula, it is observed average of GFR in both of two groups were in normal range (GFR > $60 \mathrm{~mL} / \mathrm{min}$ ), although it was significantly higher in control group $(\mathrm{P}<0.05)$. In spite of normal creatinine in patients, the urine output percentage was lower than control group $(\mathrm{P}<0.05)$. In following, calculation of free water clearance showed it was significantly lower patient group $(\mathrm{P}<0.05)$.

Based on Pearson correlation test in patient group, there wasn't significant correlation among E-CH2O and CCl and GFRest $(\mathrm{P}>0.05)$. We also checked correlation test among urine output percentage with $\mathrm{E}_{-} \mathrm{CH}_{2} \mathrm{O}$, and $\mathrm{CrCl}$. The results showed significant correlation among them $(\mathrm{P}$ $<0.05)$. There wasn't correlation between urine output percentage and GFRest in patients $(\mathrm{P}>0.05)$

\section{Discussion}

In this study, we tried to evaluate glomerular and tubular function tests in renal transplant recipients and compared the results in healthy controls. The study was conducted in kidney transplant recipients who had acceptable graft function. As in all of them serum creatinine was less than $1.5 \mathrm{mg} / \mathrm{dL}$ (in normal limit based on reference lab test).The results of estGFR based on Cockroft-Gault formula, showed that in all of patients, GFR was more than $60 \mathrm{~mL} / \mathrm{min}$ (in normal range). Then we can conclude that graft function was preserved almost well in these patients, although their results were significantly was lower than control group.
Schwarz et al. did protocol biopsies of grafts in renal transplant patients with normal serum creatinine. They found signs of chronic allograft nephropathy- interstitial fibrosis and inflammation, mesangial sclerosis, and tubular atrophy [5, 6].

It is assumed that evaluation of electrolyte free water clearance $\left(\mathrm{E}-\mathrm{CH}_{2} \mathrm{O}\right)$ gives us useful data about of renal distal tubule function in euvolumic condition. It is obvious E$\mathrm{CH}_{2} \mathrm{O}$ diminished if there is diminished Water input to the loop of Henle or increased Anti Dieurtic Hormone (ADH) secretion [3]. If the patient is hydrated enough and there isn't any stimulation for ADH secretion, then $\mathrm{E}-\mathrm{CH}_{2} \mathrm{O}$ acts as a reflection of tubular function and it can be used for detection of graft damage as creatinine clearance (CCL). Based on previous data, it has been suggested these structural damages in graft tissue lead to tubular dysfunction even before GFR reduction [4]. As our patients that were well hydrated, so it is possible to assume $\mathrm{E}-\mathrm{CH}_{2} \mathrm{O}$ as a reflection of tubular function.

All of our patients were taking several immunosuppressive drugs, which consisted of Cyclosporine, Mycophenolatemofetile, and prednisolone. It is proven that cyclosporine usage is associated with both functional and structural nephropathy in kidney transplant recipients [7]. Then lowerE- $\mathrm{CH}_{2} \mathrm{O}$ in the patients can be explained by long term effect of cyclosporine in the graft.

For better differentiation of these etiologies, we have to do kidney biopsy. One of the limitations of our study was lack of biopsy proven results for chronic rejection, cyclosporine toxicity, or both together $[8,9]$.

The main objective of our study was to evaluate free water excretion capacity of renal transplant patients. We simultaneously calculated $3 \mathrm{~h}$. creatinine clearance. It is obvious that $3 \mathrm{~h}$ creatinine clearance is not as reliable as 24hours evaluation, and it is another limitation of our study. As the results showed, in spite of normal range of creatinine clearance in patient group, $\mathrm{E}-\mathrm{H}_{2} \mathrm{O}$ was significantly lower than control group. We can conclude that it can be happened before reduction of creatinine clearance due to subclinical damages of tubules. Intact glomerular function may be demonstrated by normal GFR or creatinine clearance.

The values of urine output among renal transplant patients were significantly lower than healthy controls. It had significant correlation with both $\mathrm{CrCl}$ and $\mathrm{E}-\mathrm{H}_{2} \mathrm{O}$. It can be explained by means of urine output is a part of their formula.

This study demonstrated that $\mathrm{E}-\mathrm{CH}_{2} \mathrm{O}$ has been decreased in stable renal transplant patients in comparison with control group when there wasn't any difference between $3 \mathrm{~h}$ - $\mathrm{CCl}$ in two groups.

E- $\mathrm{CH}_{2} \mathrm{O}$ may act as an indicator of graft dysfunction 
even sooner than $3 \mathrm{~h}-\mathrm{CCl}$ in euvolumic transplant patients.

\section{Acknowledgments}

This study was the result of an internal medicine resident (Mohammad Reza Reyahi) thesis proposal and financially supported by the research vice chancellor of Mashhad University of Medical Sciences.

\section{Footnotes}

Authors' Contribution: Abbasali Zeraati, analysis and interpretation of them; Maryam Hami: conception and design, drafting the article and revising it; Farzaneh Sharifipour, final approval of the version; Mohammad Reza Reyahi, acquisition of data.

Funding/Support: The office of vice chancellor for Research of Mashhad University of Medical Sciences.

\section{References}

1. Longo D, Kasper D, Jameson J. Harrison's principles of internal medicine. New York: McGraw Hill; 2011.
2. Rose BD. Clinical physiology of acid-base and electrolyte disorders. McGraw-Hill; 1977.

3. Rose BD, Post TW. Renal water excretion and reabsorption Available from: http://sinalib.ir/uptodate/contents/mobipreview.htm?2/52/ 2886/abstract/1

4. Tekgunduz E, Apaydin S, Seyahi N, Altiparmak MR. Electrolyte free water clearance could be an early sign of renal dysfunction in renal transplant patients. Transplant Proc. 2009;41(9):3726-30. doi: 10.1016/j.transproceed.2009.06.224. [PubMed: 19917375].

5. Schwarz A, Mengel M, Gwinner W, Eisenberger U, Hiss M, Radermacher J, et al. Protocol biopsy program after renal transplantation: structure and first results. Transplant Proc. 2002;34(6):2238-9. [PubMed: 12270381].

6. Freese P, Svalander CT, Mölne J, Nordén G, Nyberg G. Chronic allograft nephropathy-biopsy findings and outcome. Nephrol Dialysis Transplant. 2001;16(12):2401-6.

7. Khanna A, Plummer M, Bromberek C. Expression ofTGF-beta and fibrogenic genes in transplant recipients withtacrolimus and cyclosporine nephrotoxicity. Kidney Int. 2002;62(6):2257-63.

8. Johnson RW. The clinical impact of nephrotoxicity in renal transplantation. Transplantation. 2000;69(12 Suppl):SS14-7. [PubMed: 10910258].

9. Khanna A, Plummer M, Bromberek C, Bresnahan B, Hariharan S. Expression of TGF-beta and fibrogenic genes in transplant recipients with tacrolimus and cyclosporine nephrotoxicity. Kidney Int 2002;62(6):2257-63. doi: 10.1046/j.1523-1755.2002.00668.x. [PubMed: $12427154]$ 